\title{
High-Cycle Fatigue Behavior of a Self-tapping Timber Screw Under Axial Tensile Loading
}

\author{
P. Niebuhr (1) M. Sieder
}

Submitted: 9 March 2020/ Accepted: 16 March 2020/Published online: 4 April 2020

(C) The Author(s) 2020

\begin{abstract}
The high-cycle fatigue behavior of a self-tapping timber screw is examined for axial tensile loading with $R=0.1$. Based on 71 fatigue tests in the finite-life and long-life regime, Wöhler curves are derived for the failure modes thread area failure and head tear off. Comparisons with existing results of similar tests show equal behavior in the long-life regime and slight differences in the finite-life regime which cannot convincingly be attributed exclusively to either varying testing conditions or differences in the examined population. The fatigue verification according to EN 1993-1-9, detail category 50, is found to be highly conservative, whereas detail category 100 is shown to overestimate the observed fatigue behavior in the finitelife regime. Adding to existing observations on the fatigue behavior of a self-tapping screw, a first assessment of the decisiveness of geometrical and procedural differences in the screws can be made.
\end{abstract}

Keywords High-cycle fatigue - Fasteners ·

Mechanical testing - Fatigue resistance

\section{Introduction}

General Introduction

The societal demand for increased sustainability in the construction sector, combined with the development of novel construction solutions and wooden or wood-based

P. Niebuhr $(\varangle) \cdot$ M. Sieder

Institute of Building Construction and Timber Structures

(iBHolz), Technische Universität Braunschweig,

Schleinitzstraße 21A, 38106 Braunschweig, Germany

e-mail: p.niebuhr@tu-braunschweig.de materials, leads to an increased application of timber, also in structures that are generally associated with steel or reinforced concrete. This includes constructions that are subjected to repeated loads that require the consideration of material fatigue as a possible cause of failure (e.g., towers for wind energy plants, cf. [1-5], or heavy duty road bridges, cf. [6-9]).

Self-tapping screws have been well-established fasteners in timber construction for several years with a wide range of applications, e.g., as high-performance fasteners as well as in applications as reinforcement for wooden parts under shear or transverse loads. The application of self-tapping screws under fatigue relevant loads is generally not possible in the European Union at the moment, because respective assessment documents only allow the application under static or quasi-static loads (see, e.g., [10]), due to a lack of knowledge of the fatigue behavior of these fasteners and the respective connections or reinforcements.

Scope and Research Context

The available literature on the fatigue behavior of timber screws and respective connections is extremely limited. Most sources examine conventional timber screws with dimensions that are not reasonable for structural engineering applications (e.g., [11-13]). The peculiar material, production process and geometry of self-tapping screws (see, e.g., [14] for an extensive description of these parameters) further indicate that a separate examination of their fatigue behavior is necessary. First dedicated tests of the fatigue behavior of a self-tapping screw under axial tensile load $(R=0.56)$ have been described by Ringhofer [14] and Ringhofer et al. [15] (both based on [16]); the derived Wöhler diagram is shown in Fig. 1. Further, 
Stamatopoulos and Malo [17] describe a preliminary study of the withdrawal behavior of threaded rods under cyclic axial load $(R=0.1)$, obtaining a first estimation of a respective Wöhler diagram which is shown in Fig. 2.

Failure of connections with self-tapping screws under (mainly) axial tensile load can occur through several mechanisms. These can be grossly distinguished in failure of the bond between screw and wood (withdrawal of the screw) and tensile failure of the screw, where the latter can be broken down further into tensile failure in the threaded area, in the unthreaded shank area (primarily for partially threaded screws), and at the screw head (head tear off, dependent on the kind of load introduction). In this contribution, tensile failure of the screw is examined. The particular emphasis was on failure in the thread area, a considerable amount of observed failures, however, occurred as head tear off, which is why this failure mechanism will also be considered in the evaluation of the results. Further investigations are needed to examine other failure mechanisms, especially the withdrawal behavior, but also the behavior of connections with screws under lateral load or combined loading. These will be part of future contributions.

As mentioned above, an examination of the fatigue behavior of a self-tapping screw under axial tensile load has already been performed by Ringhofer et al. (see $[14,15])$. Differences in material, geometry, hardening and production processes, etc. (particularly varying between different manufacturers) presumably omit the application of these results to other than the investigated screw with a nominal outer thread diameter of $d_{n}=8 \mathrm{~mm}$ and a length of $l=240 \mathrm{~mm}$. This reasons the investigation of the behavior of a different screw.

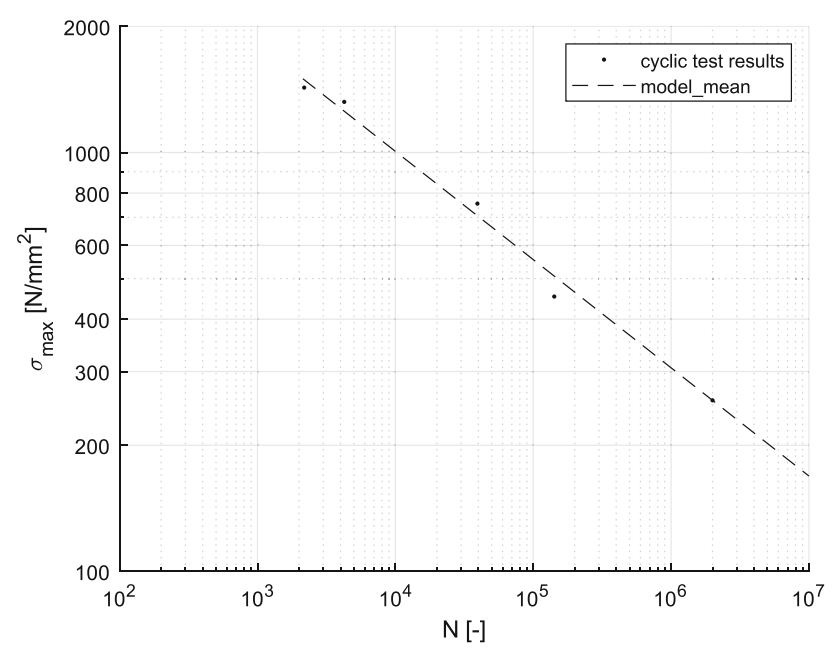

Fig. 1 Wöhler diagram for 8-mm screw under axial tensile loading $(R=0.56)$, data from Ringhofer et al. $[14,15]$

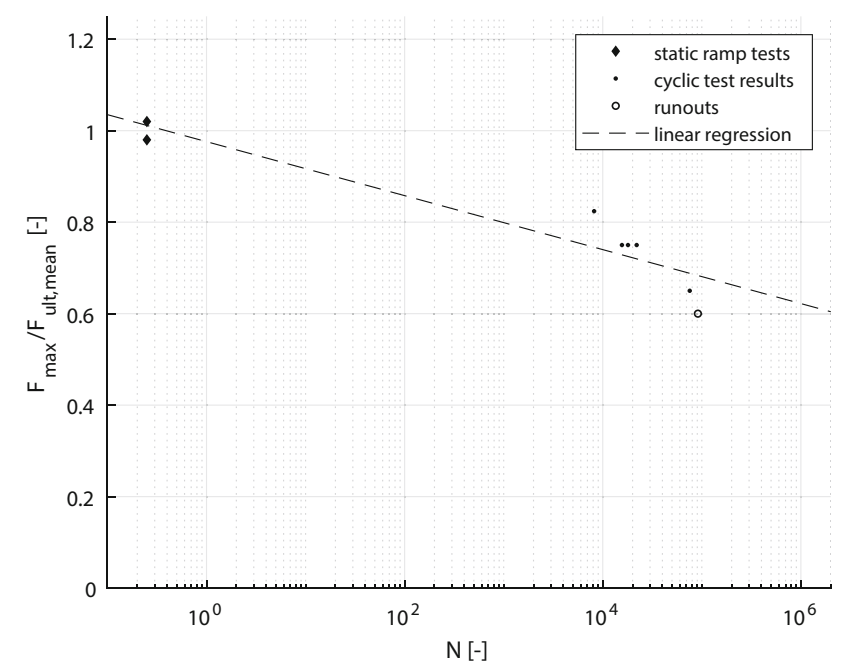

Fig. 2 Wöhler diagram for withdrawal of threaded rods, data from [17]

The tests at hand serve as the basis for further tests with wood-wood connections that expose the screw to various loading conditions (e.g., lateral or axial, see above) and will be performed with a stress ratio of $R=F_{\min } / F_{\max }=$ 0.1 , which is close to the assumed most damaging nonreversed loading scenario for wood (cf. [18, 19]). Hence, the axial tests described here are performed with $R=0.1$ as well, which has to be noted as a deviation from the finitelife tests of Ringhofer et al. with $R=0.56[14,15]$ and will be considered in the comparison of the respective results.

\section{Materials and Methods}

The investigated screw is a fully threaded self-tapping timber screw according to ETA-12/0114 [10] with a nominal outer thread diameter of $d_{n}=6 \mathrm{~mm}$ and a length of $l=120 \mathrm{~mm}$ with a cylindric head. The mean values of core diameter, outer thread diameter, pitch, flank inclination angle and head diameter have been determined as $d_{c}=4.01 \mathrm{~mm}, d=5.96 \mathrm{~mm}, \quad p=3.60 \mathrm{~mm}, \quad v=39.59^{\circ}$ and $d_{k}=8.15 \mathrm{~mm}$. All values lie within the tolerances given in the respective assessment [10]. The tensile strength of the material was tested in 11 monotonic ramp tests and was determined as $\sigma_{\mathrm{u} \text {,mean }}=1236.9 \mathrm{~N} / \mathrm{mm}^{2}$ with $\mathrm{CV}=1.36 \%$. Considering an effective cross section of $A_{p l, N}=12.857 \mathrm{~mm}^{2}$ for axial loading (cf. [14] Eq. (3.93)(3.95)), the mean tensile capacity of the screw is assumed as $F_{\mathrm{u} \text {,mean }}=15.903 \mathrm{kN}$.

The test setup for the fatigue tests resembles the setup shown in [14-16], featuring a fixed support at the tip and a hinged support at the head. The fixed support at the tip was realized with two steel members that were milled to receive the threads of the screw in oversized grooves and allow 
clamping only the shaft. The hinged support at the head was executed with a head adaptor that acted as a support for the cylindric head, see Fig. 3.

Figure 4 shows the full test setup, with the hinged head support at the bottom and the fixed tip support at the top. It has to be noted that the alignment of the specimen was fixed only in one direction (toward the camera in Fig. 4) and had to be manually adjusted in the other direction. Although this was done with great care and using a reference square, the existence of a considerable tilt of the specimen axis with regard to the load axis cannot be neglected. This tilt is assumed to result in increased stress in the specimen, on a global scale due to bending in the thread area (maximal at the fixed support), and locally at the screw head due to uneven load introduction. Hence, the observed load cycle numbers are seen as conservative on trend, albeit a moderate scatter of the results suggests that the influence of an unwanted tilt of the specimen has been small in the described tests.

The experimental program for the fatigue tests is shown in Table 1. It is generally based on the suggestions in DIN 50100 [20] and DIN 969 [21] and comprises three series in the finite-life regime and one series following the staircase procedure to explore the long-life fatigue strength (LLF strength, formerly described as fatigue limit, cf. [22]).

The threshold load cycle number for runouts in Series $\mathrm{S}_{\mathrm{LLF}}$ was chosen as $N_{G}=2.0 E 6$. Some of the tests in this series, however, were terminated at considerably higher load cycle numbers, partially continuing up to $N=1.0 E 7$, cf. Table 4 in the Appendix. Given the assumption of lognormal distributed results, the logarithmic distances that are suggested in DIN 50100 [20] for the staircase tests seem more plausible than the constant distances suggested in DIN 969 [21]. Hence, assuming the standard deviation of the population as $s_{\log L, G G}=0.050$ (generally given for screws in [20]), a logarithmic distance between the load levels was chosen and set to $d_{\log }=1.122$. All cyclic tests were performed at MFPA Leipzig $\mathrm{GmbH}$ on a walter + bai servo-hydraulic test rig (type LFV-5) with a maximum capacity of $7.5 \mathrm{kN}$.

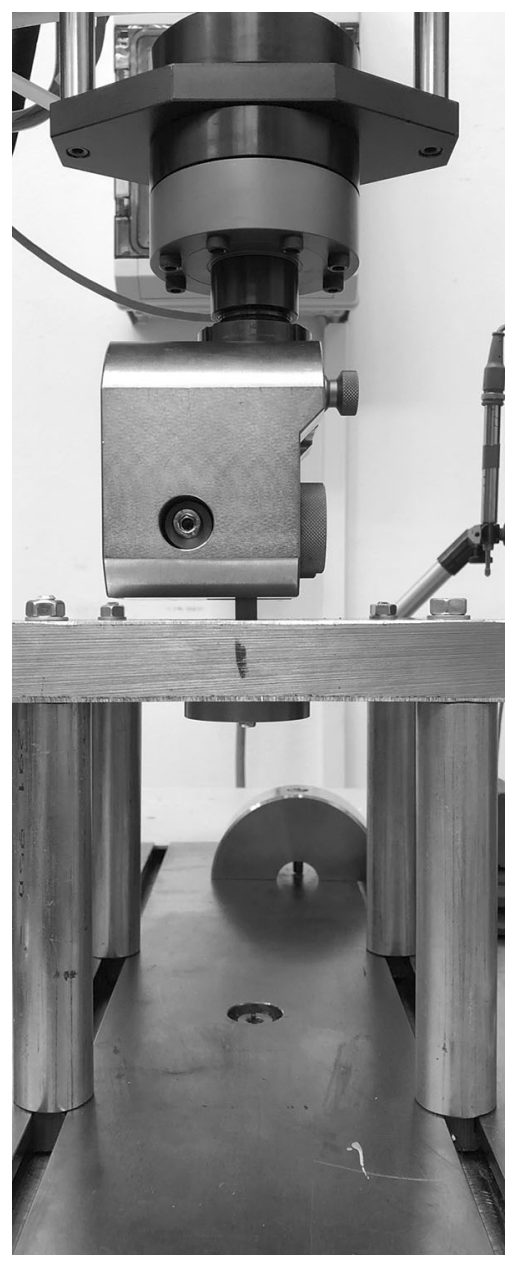

Fig. 4 Test setup, hinged head support at bottom, fixed tip support at top

Table 1 Experimental program

\begin{tabular}{lccccl}
\hline & $n(-)$ & $N_{\text {est }}(-)$ & $S=F_{\text {max }} / F_{\text {ult }}(-)$ & $R=F_{\min } / F_{\max }(-)$ & $f(\mathrm{~Hz})$ \\
\hline $\mathrm{S}_{044}$ & 14 & $2.0 E 4$ & 0.44 & 0.1 & 20 \\
$\mathrm{~S}_{032}$ & 22 & $4.0 E 4$ & 0.32 & 0.1 & 20 \\
$\mathrm{~S}_{023}$ & 20 & $1.5 E 5$ & 0.23 & 0.1 & $20-30$ \\
$\mathrm{~S}_{\mathrm{LLF}}$ & 15 & $2.0 E 6$ & $0.08-0.16$ & 0.1 & 30 \\
\hline
\end{tabular}

Fig. 3 Steel members and adaptor for fixed and hinged support (rotated $90^{\circ}$ )

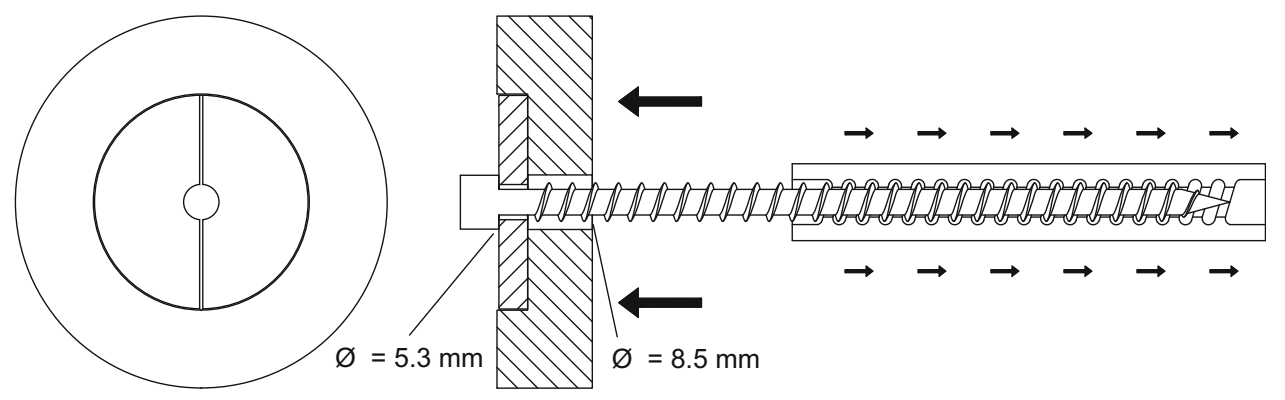


Table 2 Summarized results of the finite-life tests

\begin{tabular}{cccccccccc}
\hline & & \multicolumn{3}{c}{ Failure in thread area } & & \multicolumn{3}{c}{ Head tear off } \\
& $\begin{array}{c}\sigma_{\mathrm{a}} \\
\left(\mathrm{N} / \mathrm{mm}^{2}\right)\end{array}$ & $\begin{array}{c}n \\
(-)\end{array}$ & $\begin{array}{c}N_{50 \%} \\
(-)\end{array}$ & $\begin{array}{c}S_{\log N, \text { corr }}^{\mathrm{a}} \\
(-)\end{array}$ & & $\begin{array}{c}n \\
(-)\end{array}$ & $\begin{array}{c}N_{50 \%} \\
(-)\end{array}$ & $\begin{array}{c}S_{\log N, \text { corr }}^{\mathrm{a}} \\
(-)\end{array}$ \\
\hline $\mathrm{S}_{044}$ & 247.1 & 10 & $1.91 E 4$ & 0.0574 & & 4 & $1.93 E 4$ & 0.0640 \\
$\mathrm{~S}_{032}$ & 176.5 & 10 & $4.51 E 4$ & 0.1127 & & 12 & $4.07 E 4$ & 0.0789 \\
$\mathrm{~S}_{023}$ & 130.6 & 9 & $2.09 E 5$ & 0.0780 & & 9 & $1.15 E 5$ & 0.1127 \\
\hline
\end{tabular}

${ }^{\mathrm{a}}$ Corrected according to Martin et al. [25] to compensate for limited sample size

\section{Results}

With the described test setup, both possible failure modes (failure in thread area, head tear off) were observed in the finite-life regime (Fig. 5) and will be distinguished in the evaluation. In Series $S_{L L F}$, all failures occurred in the thread area.

\section{Thread Area Failure}

Based on a Grubbs test for the detection of outliers [23] with a significance level of $1 \%$, one test (in Series $\mathrm{S}_{023}$ ) with a remarkably low load cycle number $(N=89,600)$ was excluded from the evaluation. Considering this truncation, a Lilliefors test for normal distribution [24] was successfully performed with a significance level of $1 \%$ for the logarithmic data of all data sets.

While the individual results of the tests are found in Tables 3 and 4 in the Appendix, Table 2 contains a summary of the observed load cycle numbers at failure. All statistical values were determined assuming a normal distribution of the logarithmic data.

The evaluation of the tests in Series $S_{L L F}$ yields a bearable stress amplitude of $\sigma_{\mathrm{a}, 2 E 6 \text {, mean }}=61.9 \mathrm{~N} / \mathrm{mm}^{2}$ at the chosen threshold of $N_{\mathrm{G}}=2.0 E 6$. The scatter of the results is significant $\left(s_{\log L}=1.4918\right)$, probably because of an oversized distance between the load levels or an undersized sample [20]. A statistical evaluation of this data set does not seem appropriate and is neglected. Hence, the Wöhler diagrams in Figs. 6 and 7 contain no estimation for failure probabilities other than $P_{A}=50 \%$ outside the domain covered by Series $\mathrm{S}_{044}, \mathrm{~S}_{032}, \mathrm{~S}_{023}$.

Deriving the $50 \%$-line of finite life from the individual test results of Series $S_{044}, S_{032}, S_{023}$ presupposing neither the inclination of the line $k$ nor its location parameter $C$ (this approach corresponds to the pearl string method in DIN 50100 [20]) yields a line that intersects $\sigma_{\mathrm{a}, 2 E 6 \text {, mean }}$ at $N_{\mathrm{G}}=2.0 E 6$ which is above the chosen threshold for runouts $N_{\mathrm{G}}=2.0 E 6$ in Series $S_{\text {LLF. }}$. Hence, an extension of the finite-life line up to this point should be disregarded. Instead, the point

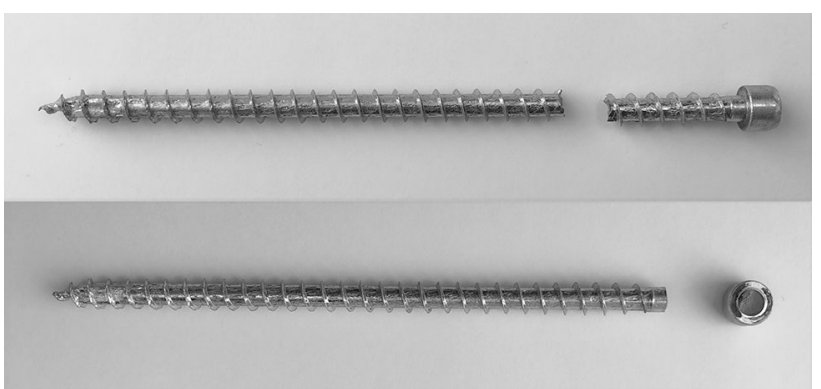

Fig. 5 Exemplary display of thread area failure (top), Specimen S35, and head tear off (bottom), Specimen S25

$\left(N=2.0 E 6 / \sigma_{\mathrm{a}}=61.92 \mathrm{~N} / \mathrm{mm}^{2}\right)$ was supposed as a fixpoint in the regression, thus deriving only the inclination $k$ from the finite-life results. With this assumption, a linear least squares regression of the logarithmic data yielded the following relation $\left(R^{2}=0.921\right)$ displayed in Fig. 6 as $P_{A}=50 \%$ :

$\log (N)=12.38-3.40 \cdot \log \left(\sigma_{a}\right)$

Assuming that the standard deviation of the population does not vary between load levels (this complies with the pearl string method in [20]), the standard deviation of the logarithmic load cycle numbers at failure was determined as $\tilde{s}_{\log N, \text { corr }}=0.1263$ (combined for Series $\mathrm{S}_{044}, \mathrm{~S}_{032}, \mathrm{~S}_{023}$, corrected according to Martin et al. [25] to compensate for the limited sample size). For the domain covered by $\mathrm{S}_{044}$, $\mathrm{S}_{032}, \mathrm{~S}_{023}$ finite-life lines for failure probabilities of $P_{A}=5 \%$ and $P_{A}=95 \%$ were derived using tabulated values for the computation of quantiles of normally distributed data and assuming the same inclination $k=3.40$. Figure 6 shows the individual test results and the derived finite-life lines. The individual standard deviation of every load level is given in Table 2. An evaluation of the test data considering the individual load levels (based on the load level method in [20]) yields a multi-linear line of finite life, see Fig. 7.

\section{Head Tear Off}

Similar to the data set with thread area failure, one test in Series $\mathrm{S}_{023}$ with head tear off was identified as an outlier $(N=11,705)$ and omitted from the evaluation (Grubbs test with significance level 1\%), and for all data sets a lognormal distribution was confirmed with a Lilliefors test (significance level 1\%).

A linear least squares regression of the individual head tear off data (here without fixed location) yielded the following equation $\left(R^{2}=0.899\right)$ :

$\log (N)=11.19-2.91 \cdot \log \left(\sigma_{a}\right)$

The test results and derived lines of finite life for are shown in Fig. 8 for a collective evaluation (pearl string 
method, $\tilde{s}_{\log N \text {,corr }}=0.0974$ ) and in Fig. 9 for an individual evaluation of the load levels (load level method). Because none of the tests in Series $S_{\mathrm{LFF}}$ led to head tear off failure, no conclusion on the bearable stress amplitude in the longlife regime can be made. The data points are, however, included as runouts in the derived Wöhler diagrams to allow for a visual impression of the position of the LLF tests.

\section{Discussion}

\section{Comparison Thread Area Failure and Head Tear Off}

Because of the nature of cylindric heads (the head diameter is barely larger than the thread diameter, cf. Figure 11), a considerable load introduction through the screw head is not to be expected in common timber-to-timber connections with cylindric head screws. Hence, the findings on the head tear off failure under cyclic loading are of limited usefulness. In steel-to-timber connections, where a discrete load introduction at the screw head is common, other head geometries such as countersunk heads together with angled washers are commonly applied. However, the share of head tear off failures in the finite-life tests (ca. 50\%) shows that this failure mode cannot be generally disregarded when considering cyclic loading.

A statistically significant influence of the location of failure within the data set with thread area failure could not be detected (F-distribution-test for trend, significance level $1 \%$, cf. [26] p. 218f). Figure 10 shows the observed load cycle numbers at failure plotted against the respective location of failure (expressed as the number of the thread, counted from head to tip) for the series in the finite-life

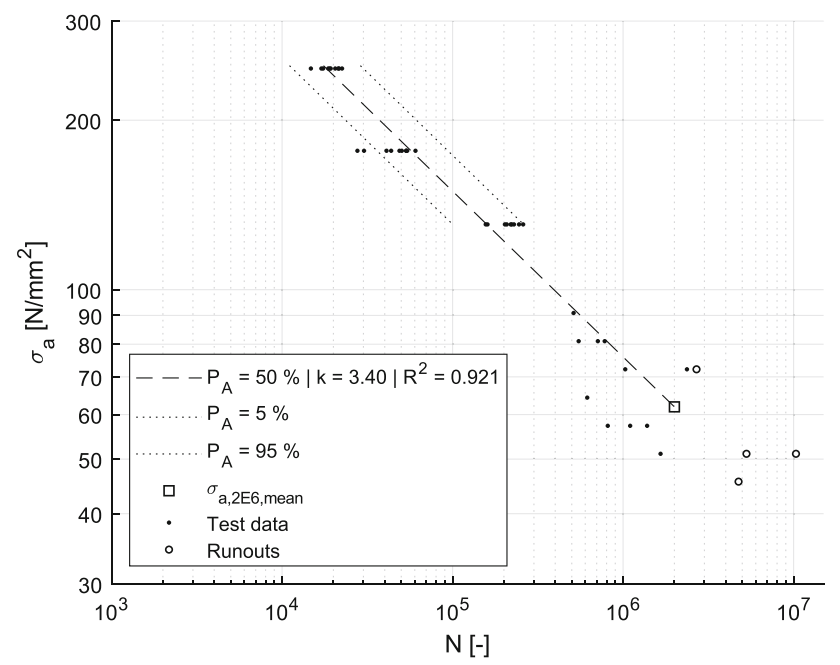

Fig. 6 Wöhler diagram for thread area failure-pearl string evaluation (location fixed) regime. To account for different load levels between series, each individual logarithmic load cycle number $i$ is normalized to the respective mean value of the logarithmic load cycle numbers in that series $j$ :

$\left(\log N_{i}\right)_{\text {norm }}=\frac{\log N_{i}}{\left(\log N_{j}\right)_{\text {mean }}}$

Comparison with Ringhofer et al.

As mentioned before, a first extensive examination of the fatigue behavior of a self-tapping timber screw under cyclic axial loading has been undertaken by Ringhofer et al. [14, 15]. The main differences in the considered specimens and test setup are:

\begin{tabular}{ll}
\hline Type of screw head & (pear head $\leftrightarrow$ cylindric head $)$ \\
Thread diameter $d$ & $(8.00 \mathrm{~mm} \leftrightarrow 5.96 \mathrm{~mm})$ \\
Core diameter $d_{\mathrm{c}}$ & $(5.12 \mathrm{~mm} \leftrightarrow 4.01 \mathrm{~mm})$ \\
Screw length $l$ & $(240 \mathrm{~mm} \leftrightarrow 120 \mathrm{~mm})$ \\
Tensile strength $\sigma_{\text {ult,mean }}$ & $\left(1437 \mathrm{~N} / \mathrm{mm}^{2} \leftrightarrow 1237 \mathrm{~N} / \mathrm{mm}^{2}\right)$ \\
Stress ratio $R$ & $(0.56 \leftrightarrow 0.10$ in finite-life \\
& regime $)$ \\
& $(\{0.90 ; 0.56 ; 0.10\} \leftrightarrow 0.10$ in \\
long-life regime $)$
\end{tabular}

The most prominent difference in the respective test results is that, despite an analogous discrete load introduction at the screw head, Ringhofer et al. do not observe any head tear off failure. This, however, can satisfactorily be explained by distinctly different head geometries, with the pear head presenting a significantly less pronounced

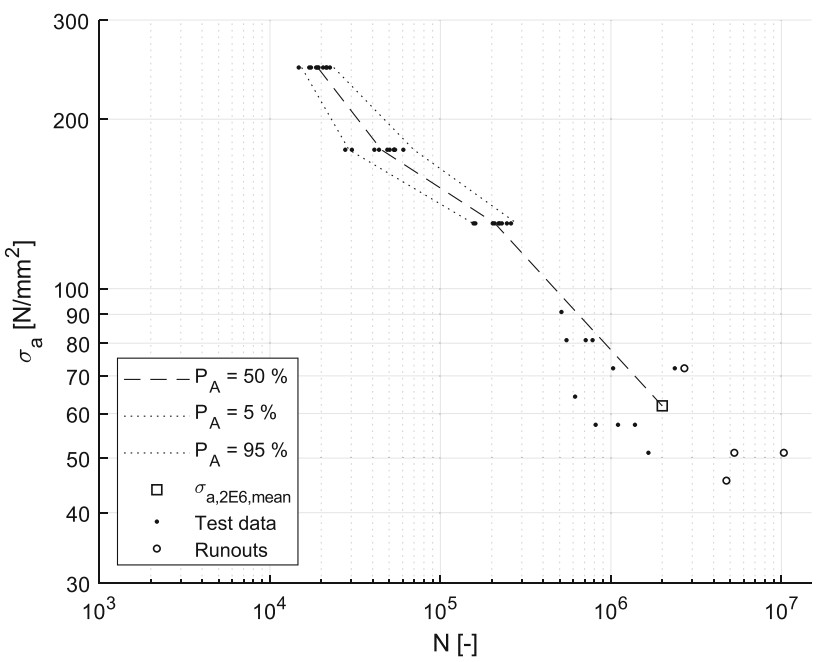

Fig. 7 Wöhler diagram for thread area failure-load level evaluation 
geometrical notch than the cylindric head. Figure 11 shows the different head geometries.

Figure 12 shows the derived Wöhler diagrams for thread area failure (cf. Figure 6) and from Ringhofer et al. $[14,15]$, the latter being transformed to the chosen $\sigma_{\mathrm{a}}-N$ coordinates. Although the curves are not exactly coincident, they are distinctively adjacent, with Ringhofer et al.'s curve consistently yielding lesser load cycle numbers for equal loading. A possible explanation for this disparity is different behaviors of two different examined popularities (i.e., screws). However, the mean results in the long-life regime (staircase method) in both examinations are noticeably similar, with $\sigma_{a, 2 E 6}=61.9 \mathrm{~N} / \mathrm{mm}^{2}$ in Series $\mathrm{S}_{\mathrm{LLF}}$ and $\sigma_{a, 2 E 6}=64.4 \mathrm{~N} / \mathrm{mm}^{2}$ for the tests with $R=0.1 \mathrm{in}$ Ringhofer et al. [14, 15] (there given as $\sigma_{\max , 2 \mathrm{E} 6 \text {,med }}=143 \mathrm{~N} / \mathrm{mm}^{2}$ ). This similarity suggests that the effect of different screws' properties (geometry, material, etc.) is probably small in the considered cases and that the differences in the obtained finite-life lines might be attributed to the difference in mean stress, i.e., stress ratio $R$. An unfavorable influence of increased mean stress is commonly assumed for metallic specimens (cf. [27]) and was also observed in the long-life tests with varying stress ratio in Ringhofer et al. [14, 15]. Assuming that the two investigated screws are comparable, a normalized constantlife diagram (Haigh form, cf. [28]) was derived from the finite-life line for thread area failure and the line given in Ringhofer et al. [14, 15], see Fig. 13. It has to be noted that the determined mean tensile strengths of both screws differ $\left(\sigma_{\text {ult }}=1237 \mathrm{~N} / \mathrm{mm}^{2}\right.$, see above, vs. $\sigma_{\text {ult }}=1437 \mathrm{~N} / \mathrm{mm}^{2}$ in $[14,15])$, which is why all stresses have been normalized to their respective ultimate stress in Fig. 13. A linear regression has been executed for several load cycle numbers $N$,

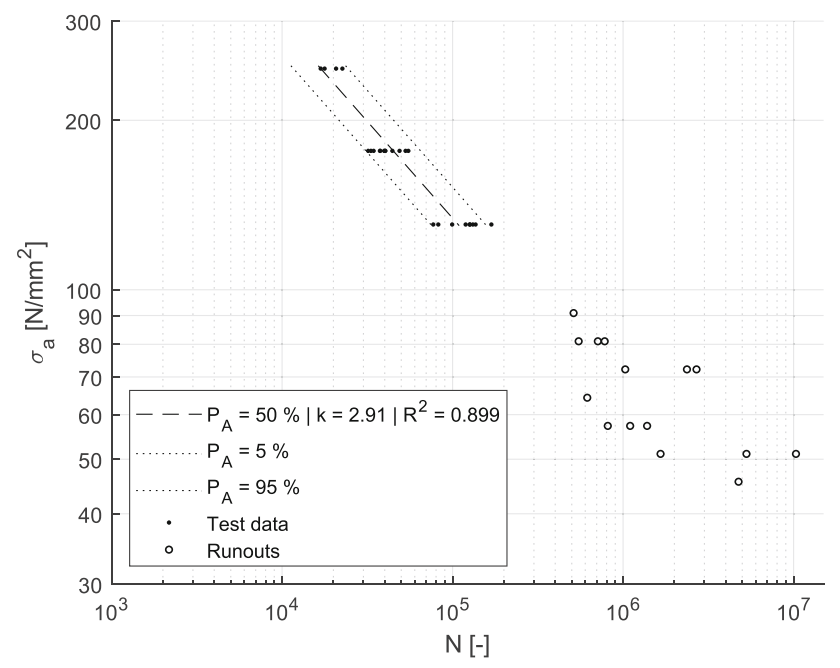

Fig. 8 Wöhler diagram for head tear off-pearl string evaluation always including $\left(\left[\sigma_{\text {mean }} / \sigma_{\text {ult }}=1\right] /\left[\sigma_{\mathrm{a}} / \sigma_{\text {ult }}=0\right]\right)$ in the regression. It can be seen that a linear relation between mean stress and stress amplitude, commonly referred to as Goodman relation (based on [29]) and assumed to yield a conservative estimation of the relation (cf., e.g., [27, 30, 31], describes the experimental results with a certain goodness, though not in a strictly conservative way.

Even though an exact congruence of the Goodman lines with the obtained finite-life lines was not expected, the fact that the linear regression represents the results in Ringhofer et al. $[14,15]$ on the unsafe side indicates that the effect of mean stress cannot fully or satisfactorily explain different results obtained for different screws as shown in Fig. 12 (assuming that any tolerable deviation from congruence would be on the safe side, following the described consensus on the conservativeness of the Gerber relation). It

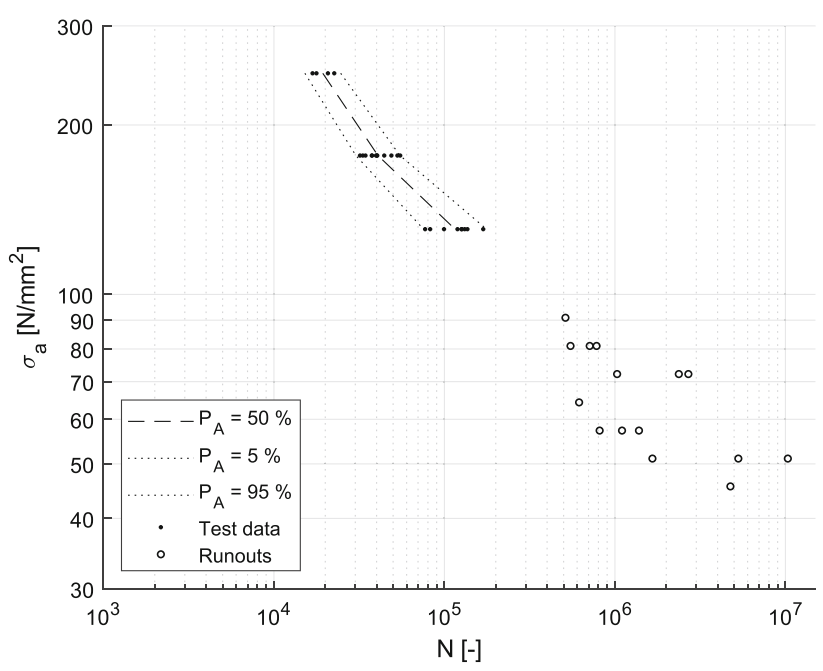

Fig. 9 Wöhler diagram for head tear off-load level evaluation

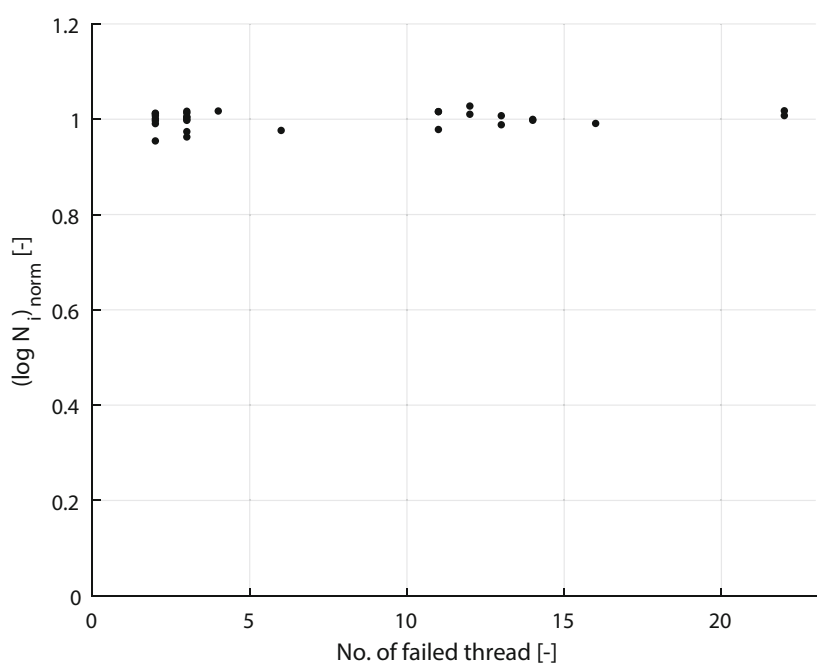

Fig. 10 Influence of the location of failure on the bearable load cycle number (head tear off excluded) 

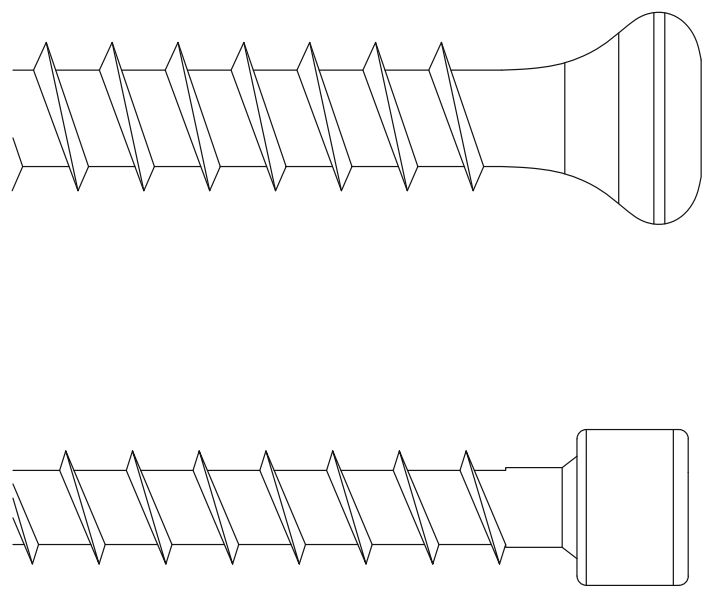

Fig. 11 Geometry of pear head (top), based on [15], and cylindric head (bottom)

has to be assumed that the differences in geometry and possibly in material (see different tensile strengths) cannot be disregarded in the estimation of the finite-life fatigue behavior of the considered screws.

\section{Comparison with EN 1993-1-9}

Figure 14 shows the obtained Wöhler curve for thread area failure along with the Wöhler curve for fatigue verification of bolts and rods under tensile loading in EN 1993-1-9 [32] (detail category 50 according to EN 1993-1-9 Table 8.1). Note 1 to EN 1993-1-9 7.1(3) states that when the association of specific constructional details to detail categories is based on experiments, a data representation with a probability of failure of $P_{A}=5 \%$ has been targeted, which is why the $5 \%$-line of the obtained data is also included to allow for a direct comparison. It is obvious that a verification that handles the examined screw as a regular steel bolt or rod will significantly underestimate the fastener's performance, as was also stated by Ringhofer et al. $[14,15]$. There, detail category 100 was identified as capable of a more appropriate representation of the observed behavior. This, while true for the reference endurance of $N=2.0 E 6$, cannot be declared for the obtained results in the finite-life regime, since the curve lies on the unsafe side of the obtained 5\%-line, see Fig. 14.

At this point, it has to be noted that according to DIN 50100 8.2.1 [20] the assumption of log-normal distributed load cycle data has only been confirmed for failure probabilities $10 \% \leq P_{\mathrm{a}} \leq 90 \%$, which is why the given regression lines with $P_{A}=5 \%$ and $P_{A}=95 \%$ (cf. Figs. 6, 7, 8, 9, and 14) have to be interpreted with caution. However, the general conclusion that detail category 50 is extremely conservative, while detail category 100 cannot unconditionally be declared safe, is untouched by this restriction.

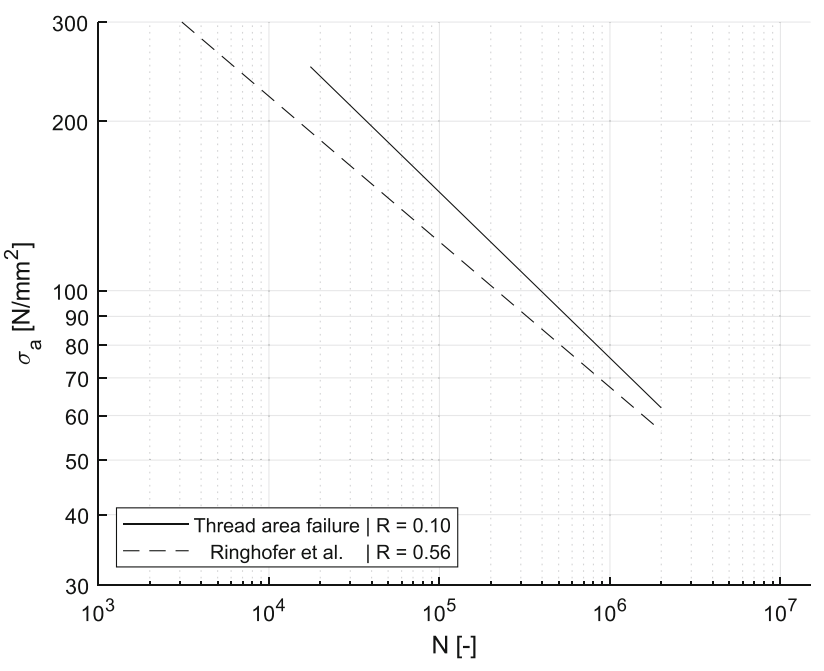

Fig. 12 Comparison with Ringhofer et al. [14, 15]; both graphs show $P_{A}=50 \%$

\section{Conclusions}

The fatigue behavior of a self-tapping timber screw under axial tensile load has been examined in the finite-life and in the long-life regime. On the basis of 71 cyclic tests, finitelife lines were obtained separately for failure in the thread area as well as head tear off failure.

A comparison with existing results from similar tests with a different screw and different stress ratio showed that the fatigue behavior differs only to a limited extent. Nevertheless, the differences in behavior could not be attributed exclusively to either varying testing conditions (mean stress) or differences in the examined population (screw). The data suggests that with an appropriate data basis a general consideration of different self-tapping screws under varying loading conditions (e.g., in the form of a general detail category as in EN 1993-1-9 [32]) might be possible without excessively conservative results. However, considerably more tests with a dedicated variation of selected parameters would be required to allow for such an approach.

The considerable amount of head tear off failures in the finite-life tests indicates that this failure mode cannot generally be disregarded, although failure was observed under a combination of corresponding conditions (discrete load introduction and pronounced geometrical notch). As a general conclusion, head tear off should be considered as a possible failure mode in verification, when a considerable load introduction at the head is given, and the specific head geometry has not been found to be insensitive to cyclic loading (e.g., the specimen in Ringhofer et al. [14, 15]). This could be the case in connections with screws with large washer heads or collared heads, or in steel-to-timber connections with steel plates as outer members. 


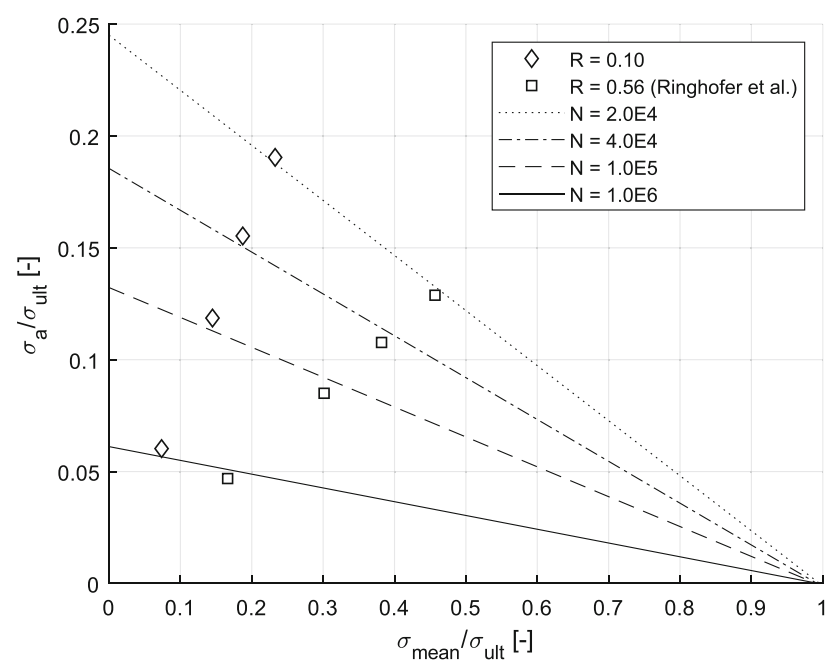

Fig. 13 Constant-life diagram derived from the obtained finite-life line and the results in Ringhofer et al. [14, 15]

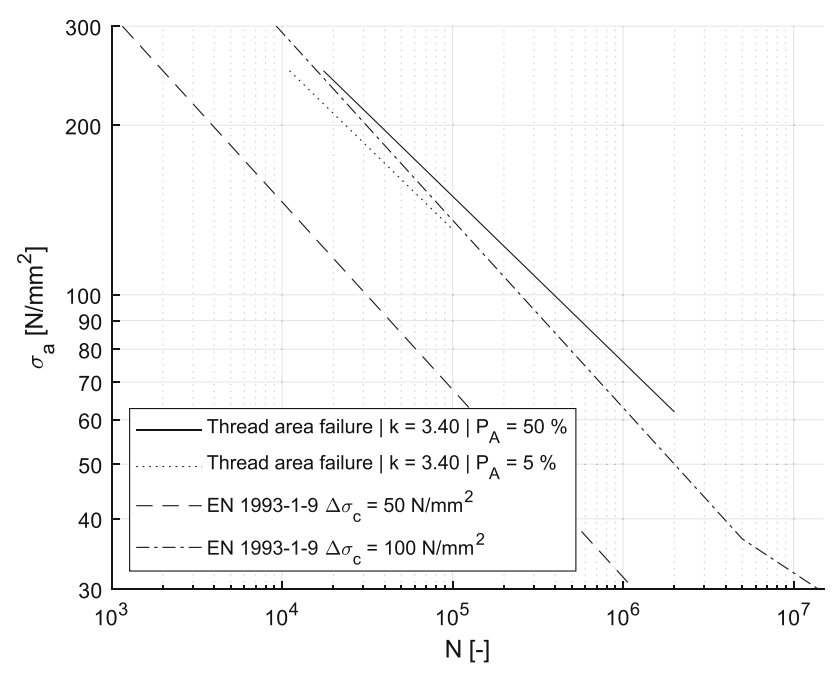

Fig. 14 Comparison with EN 1993-1-9

In the context of verification of self-tapping screws under cyclic axial loading, the behavior of the examined screw under the given circumstances can satisfactorily be described with the obtained results. For a sufficient characterization of connections with these fasteners, subsequent tests of the withdrawal behavior of the screw, as presented by Stamatopoulos and Malo [17] for threaded rods, will be performed to allow for a holistic consideration of possible failure modes in verification. Preliminary tests showed that for high stress levels in the bond between screw and wood $S=F_{\max } / F_{\text {ult }}>0.7$ withdrawal is observed as the decisive failure mode in fatigue, whereas with decreasing bond loading, tensile failure in the screw becomes decisive for the bearable number of load cycles. This transition area will be examined extensively to allow for a clean differentiation of failure modes in design.

As stated by Ringhofer et al. [14, 15], connections with screws under axial tensile loading are commonly realized with screws inclined to the direction of load which results in bending of the screw additional to the axial loading considered here. In another subsequent study, the fatigue behavior of timber-to-timber connections with laterally loaded screws will be examined, allowing for an assessment of the behavior of the screws under cyclic bending which can be joined with the obtained knowledge of the screw's behavior under exclusively axial loading to estimate the behavior under the described combined loading in connections with inclined screws.

Acknowledgments Open Access funding provided by Projekt DEAL. This work was funded by the Deutsche Forschungsgemeinschaft (DFG, German Research Foundation)-397985109. The authors wish to thank SPAX International GmbH \& Co. KG for the provision of the tested specimens.

\section{Compliance with Ethical Standards}

Conflict of interest None.

Open Access This article is licensed under a Creative Commons Attribution 4.0 International License, which permits use, sharing, adaptation, distribution and reproduction in any medium or format, as long as you give appropriate credit to the original author(s) and the source, provide a link to the Creative Commons licence, and indicate if changes were made. The images or other third party material in this article are included in the article's Creative Commons licence, unless indicated otherwise in a credit line to the material. If material is not included in the article's Creative Commons licence and your intended use is not permitted by statutory regulation or exceeds the permitted use, you will need to obtain permission directly from the copyright holder. To view a copy of this licence, visit http://creativecommons. org/licenses/by/4.0/.

\section{Appendix}

See Tables 3 and 4. 
Table 3 Results of series $\mathrm{S}_{044}, \mathrm{~S}_{032}, \mathrm{~S}_{023}$

\begin{tabular}{|c|c|c|c|c|c|c|c|c|}
\hline \multicolumn{3}{|c|}{$\mathrm{S}_{044}$} & \multicolumn{3}{|c|}{$\mathrm{S}_{032}$} & \multicolumn{3}{|c|}{$\mathrm{S}_{023}$} \\
\hline & $N(-)$ & Failure & & $N(-)$ & Failure & & $N(-)$ & Fails \\
\hline 1 & $1.70 E 4$ & Thread & S14 & $4.43 E 4$ & Head & S34 & $1.68 E 5$ & Head \\
\hline S2 & $1.48 E 4$ & Thread & S15 & $3.44 E 4$ & Head & S35 & $1.56 E 5$ & Thread \\
\hline S3 & $1.74 E 4$ & Thread & S16 & $5.30 E 4$ & Head & S36 & $1.60 E 5$ & Thread \\
\hline S4 & $1.90 E 4$ & Thread & S17 & $3.02 E 4$ & Thread & S40 & $1.26 E 5$ & Head \\
\hline S5 & $2.25 E 4$ & Thread & S18 & $2.77 E 4$ & Thread & S41 & $2.22 E 5$ & Thread \\
\hline S6 & $2.05 E 4$ & Thread & S19 & $4.36 E 4$ & Thread & S42 & $0.77 E 5$ & Head \\
\hline S7 & $1.68 E 4$ & Head & S20 & $4.88 E 4$ & Head & S43 & $2.29 E 5$ & Thread \\
\hline S8 & $1.86 E 4$ & Thread & S21 & $4.03 E 4$ & Head & $\mathrm{S} 44^{\mathrm{a}}$ & $0.90 E 5$ & Threa \\
\hline S9 & $2.07 E 4$ & Head & S22 & $4.88 E 4$ & Thread & S45 & $0.82 E 5$ & Head \\
\hline S10 & $2.26 E 4$ & Head & S23 & $6.06 E 4$ & Thread & $\mathrm{S} 46^{\mathrm{a}}$ & $0.12 E 5$ & Head \\
\hline S11 & $2.46 E 4$ & $\mathrm{Th}$ & S24 & $3.20 E 4$ & $\mathrm{H}$ & S47 & $E 5$ & ead \\
\hline $\mathrm{S} 12$ & $2.13 E 4$ & Thread & S25 & $4.02 E 4$ & Inda & S48 & $E 5$ & Itea \\
\hline S13 & $1.93 E 4$ & Thread & S26 & $3.77 E 4$ & $\mathrm{He}$ & S49 & $1.26 E 5$ & Head \\
\hline S37 & $1.78 E 4$ & Head & S27 & $5.35 E 4$ & ead & S50 & $1.19 E 5$ & Head \\
\hline$\ldots$ & $\ldots$ & 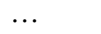 & S28 & $3.32 E 4$ & $\mathrm{Hea}$ & S51 & $2.08 E 5$ & $\mathrm{ad}$ \\
\hline$\ldots$ & $\ldots$ & $\ldots$ & S29 & $5.34 E 4$ & Thread & S52 & $2.19 E 5$ & Threa \\
\hline$\ldots$ & . & $\ldots$ & S30 & $5.04 E 4$ & Thread & S53 & $1.31 E 5$ & Head \\
\hline$\ldots$ & .. & $\ldots$ & S31 & $3.97 E 4$ & Head & S54 & $2.45 E 5$ & Threa \\
\hline$\ldots$ & $\ldots$ & $\ldots$ & S32 & $3.45 E 4$ & Head & S55 & $1.36 E 5$ & Head \\
\hline$\ldots$ & $\ldots$ & . & S33 & $5.42 E 4$ & Thread & S56 & $2.03 E 5$ & Threa \\
\hline$\ldots$ & $\ldots$ & 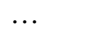 & S38 & $4.10 E 4$ & Thread & $\because$ & 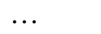 & \\
\hline$\ldots$ & $\ldots$ & $\ldots$ & S39 & $5.50 E 4$ & Head & $\ldots$ & $\ldots$ & $\ldots$ \\
\hline
\end{tabular}

${ }^{\mathrm{a} O u t l i e r}$-omitted from evaluation

Table 4 Results of series $S_{\mathrm{LFF}}$

\begin{tabular}{lccccc}
\hline & $\begin{array}{c}\text { Load level } i \\
(-)\end{array}$ & $\begin{array}{c}\sigma(\mathrm{N} / \\
\left.\mathrm{mm}^{2}\right)\end{array}$ & $\begin{array}{c}S=F_{\max } / F_{\text {ult }} \\
(-)\end{array}$ & $N(-)$ & $\begin{array}{c}\text { Runout }(y / \\
n)\end{array}$ \\
\hline $\mathrm{T} 1$ & 3 & 90.9 & 0.16 & $0.51 E 6$ & $n$ \\
$\mathrm{~T} 2$ & 2 & 81.0 & 0.15 & $0.71 E 6$ & $n$ \\
$\mathrm{~T} 3$ & 1 & 72.2 & 0.13 & $2.70 E 6$ & $\boldsymbol{y}$ \\
$\mathrm{T} 4$ & 2 & 81.0 & 0.15 & $0.55 E 6$ & $n$ \\
$\mathrm{~T} 5$ & 1 & 72.2 & 0.13 & $2.37 E 6$ & $\boldsymbol{n}^{\mathrm{a}}$ \\
$\mathrm{T} 6$ & 2 & 81.0 & 0.15 & $0.78 E 6$ & $n$ \\
$\mathrm{~T} 7$ & 1 & 72.2 & 0.13 & $1.03 E 6$ & $n$ \\
$\mathrm{~T} 8$ & 0 & 64.3 & 0.12 & $0.62 E 6$ & $n$ \\
$\mathrm{~T} 9$ & -1 & 57.3 & 0.10 & $1.38 E 6$ & $n$ \\
$\mathrm{~T} 10$ & -2 & 51.1 & 0.09 & $1.66 E 6$ & $n$ \\
$\mathrm{~T} 11$ & -3 & 45.6 & 0.08 & $4.76 E 6$ & $\boldsymbol{y}$ \\
$\mathrm{T} 12$ & -2 & 51.1 & 0.09 & $10.33 E 6$ & $\boldsymbol{y}$ \\
$\mathrm{T} 13$ & -1 & 57.3 & 0.10 & $0.81 E 6$ & $n$ \\
$\mathrm{~T} 14$ & -2 & 51.1 & 0.09 & $5.29 E 6$ & $\boldsymbol{y}$ \\
$\mathrm{T} 15$ & -1 & 57.3 & 0.10 & $1.10 E 6$ & $n$ \\
\hline
\end{tabular}

${ }^{a}$ Note that failure did occur above the chosen threshold of $N=2.0 E 6$; the specimen was, however, treated as a runout because the threshold load cycle number was reached without failure

\section{References}

1. J. Röhm, S. Brand, F. Kunz, Züblin wooden wind power tower, in Internationales Holzbau-Forum IHF 2015, Vol. 21, ed. by Forum-Holzbau (2015)

2. C. Schröder, Wooden and wood hybrid towers for wind turbines in the multi-megawatt class, in Internationales Holzbau-Forum IHF 2015, Vol. 21, ed. by Forum-Holzbau (2015)

3. Z. Christian, S. Aicher, Fatigue behaviour of timber composites and connections for ultra high wooden towers, in WCTE 2016 Conference Proceedings, ed. by J. Eberhardsteiner, W. Winter, A. Fadai, M. Pöll (2016)

4. M. Gräfe, C. Bert, S. Winter, Prestressed CLT wind-turbine towers. Bautechnik 94, 804-811 (2017)

5. M. Sieder, C. Schröder, TimberTower: Erfahrungen aus Konstruktion und Betrieb der ersten Windkraftanlage mit Holzturm, in Internationales Holzbau-Forum IHF 2019, Vol. 25, ed. by Forum-Holzbau (2019), pp. 259-272

6. M. Flach, C.D. Frenette, Wood-concrete-composite-technology in bridge construction, in WCTE 2004 Conference Proceedings, ed. by A. Ranta-Maunus, T. Toratti (2004), pp. 289-294

7. L. Meyer, C. Morzier, J.-B. Tissot, 40-ton wood-concrete composite bridges in Canton Fribourg, in Internationales HolzbauForum IHF 2005, Vol. 11, Forum-Holzbau (2005)

8. D. Lefebvre, G. Richard, Design and construction of a $160-\mathrm{Me}-$ tre-Long Wood Bridge in Mistissini, Québec, in Internationales Holzbau-Forum IHF 2014, Vol. 20, ed. by Forum-Holzbau (2014)

9. T. Rantakokko, L. Salokangas, Design of the Vihantasalmi Bridge, Finland. Struct. Eng. Int. 10, 150-152 (2000)

10. ETA-12/0114, European Technical Assessment. SPAX Self-tapping Screws. ETA-Danmark A/S (2017)

11. F.-W. Bröker, H.A. Krause, Orientierende Untersuchungen über das Haltevermögen dynamisch beanspruchter Holzschrauben. Holz als Roh- und Werkstoff 49, 381-384 (1991)

12. A. Burmester, A. Hoffmann, Schraubenhaltevermögen von Kiefern- und Fichtenholz unter langdauernder statischer und dynamischer Belastung. Die Holzbearbeitung HOB 17, 9-11 (1970)

13. T. Trübswetter, Klammern als Holzverbinder bei wechselnden Lasten. HK Holz- und Kunststoffverarbeitung 7 (1973)

14. A. Ringhofer, Axially Loaded Self-Tapping Screws in Solid Timber and Laminated Timber Products (Verlag der Technischen Universität Graz, Graz, 2017)

15. A. Ringhofer, M. Augustin, G. Schickhofer, Basic steel properties of self-tapping timber screws exposed to cyclic axial loading. Constr. Build. Mater. 211, 207-216 (2019)

16. A. Imsirovic, Untersuchungen zur Zeitfestigkeit vorwiegend axial beanspruchter selbstbohrender Holzschrauben. Master Thesis (Technische Universität Graz, 2014)

17. H. Stamatopoulos, K.A. Malo, Fatigue strength of axially loaded threaded rods embedded in glulam at $45^{\circ}$ to the grain, in Conference Proceedings: ICTB 2017, ed. by A. Gustafsson, A. Pousette, O. Hagman, M. Ekevad (2017)

18. I. Smith, E. Landis, M. Gong, Fracture and Fatigue in Wood (Wiley, Chichester, 2003)

19. H. Kreuzinger, B. Mohr, Holz und Holzverbindungen unter nicht vorwiegend ruhenden Einwirkungen (Technische Universität München, 1994)

20. DIN 50100:2016-12, Load Controlled Fatigue Testing. Execution and Evaluation of Cyclic Tests at Constant Load Amplitudes on Metallic Specimens and Components. Berlin. DIN Deutsches Institut für Normung e.V. (2016) 
21. DIN 969:1997-12, Threaded Fasteners-Axial Load Fatigue Testing-Test Methods and Evaluation of Results (DIN Deutsches Institut für Normung e.V., Berlin, 1997)

22. R. Masendorf, C. Müller, Execution and evaluation of cyclic tests at constant load amplitudes-DIN 50100:2016. Mater. Test. 60, 961-968 (2018)

23. F.E. Grubbs, Procedures for detecting outlying observations in samples. Technometrics 11, 1-21 (1969)

24. H.W. Lilliefors, On the Kolmogorov-Smirnov test for normality with mean and variance unknown. J. Am. Stat. Assoc. 62, 399402 (1967)

25. A. Martin, K. Hinkelmann, A. Esderts, Zur Auswertung von Schwingfestigkeitsversuchen im Zeitfestigkeitsbereich. Teil 2. Mater. Test. 53, 513-521 (2011)

26. M. Kühlmeyer, C. Kühlmeyer, Statistische Auswertungsmethoden für Ingenieure (Springer, Berlin, 2001)

27. J.A. Collins, Failure of Materials in Mechanical Design. Analysis, Prediction, Prevention (Wiley, New York, 1993)
28. B.P. Haigh, Report on alternating stress tests of a sample of mild steel, in British Association for the Advancement of Science, Report of the 85th Meeting (1915), pp. 163-170

29. J. Goodman, Applied Mechanics in Engineering (Longmans, Green and Co., London, 1914)

30. D. Radaj, M. Vormwald, Ermüdungsfestigkeit. Grundlagen für Ingenieure (Springer, Berlin, 2007)

31. G.P. Sendeckyj, Constant life diagrams-a historical review. Int. J. Fatigue 23, 347-353 (2001)

32. EN 1993-1-9:2005 + AC:2009, Eurocode 3: Design of Steel Structures-Part 1-9: Fatigue (CEN European Committee for Standardization, Brussels, 2009)

Publisher's Note Springer Nature remains neutral with regard to jurisdictional claims in published maps and institutional affiliations. 